\title{
AVALIAÇÃO DA QUALIDADE DE MANGA 'PALMER' TRATADA COM 1-METILCICLOPROPENO E ARMAZENADA SOB REFRIGERAÇÃO E CONDIÇÃO AMBIENTE ${ }^{1}$
}

\author{
ELLENTOEWS DOLLHOJO², CELESTE MARIAPATTO DEABREU ${ }^{3}$, \\ SIMONEABREU ASMAR ${ }^{4}$, RONALDO HISSAYUKI HOJO ${ }^{2}$, \\ ANGELITADUARTECÔRREA ${ }^{3}$,EDUARDO VALÉRIO DE BARROS VILAS BOAS ${ }^{5}$
}

RESUMO - O objetivo deste trabalho foi verificar a qualidade de mangas da cv. Palmer tratadas com 1metilciclopropeno (1-MCP) mantidas sob armazenamento refrigerado e sob armazenamento refrigerado associado à exposição à temperatura ambiente por quatro dias. $\mathrm{O}$ delineamento experimental foi inteiramente casualizado, em fatorial 3 x 6, sendo 3 níveis do fator dose de 1 -MCP $\left(0\right.$ - testemunha, 100 nL.L ${ }^{-1}$ e 150 nL.L $\left.{ }^{-1}\right)$ e 6 níveis do fator tempo de armazenamento $(0 ; 7 ; 14 ; 21 ; 28$ e 35 dias de armazenamento refrigerado, no experimento 1 , e $0 ; 7+4 ; 14+4 ; 21+4 ; 28+4$ e 35 dias de armazenamento refrigerado +4 dias sob condição ambiente, no experimento 2), com 3 repetições. Cada parcela experimental foi composta por 2 frutos. O uso de 1-MCP em mangas 'Palmer' mantidas sob refrigeração reduz as perdas de massa e ácido ascórbico, retardando, mas não impedindo o amadurecimento. O tratamento com $150 \mathrm{~nL} . \mathrm{L}^{-1}$ não é mais eficiente que o com 100 nL.L ${ }^{-1}$, pelas características químicas analisadas. As mangas 'Palmer' expostas à condição ambiente por quatro dias apresentam expressivo murchamento e perda de qualidade, com base nas análises de sólidos solúveis, açúcares solúveis e acidez titulável.

Termos para indexação: Mangifera indica L., conservação, 1-MCP, vida útil.

\section{EVALUATION OF QUALITY OF 'PALMER' MANGOES FRUIT TREATED WITH 1-METHYLCYCLOPROPENE AND STORED UNDER REFRIGERATION AND ENVIRONMENTAL CONDITIONS}

\begin{abstract}
The objective of this work was to verify the behavior of mangoes cv. Palmer treated with 1methylcyclopropene (1-MCP) stored under refrigeration and under refrigeration associate in exposure for four days at room temperature. The experiment was carried out in a completely randomly design, $3 \times 6$ factorial, with 3 levels of the factor concentration of 1-methylcyclopropene $\left(0 \mathrm{~nL} . \mathrm{L}^{-1}\right.$ - witness, $100 \mathrm{~nL} . \mathrm{L}^{-1}$ and $\left.150 \mathrm{~nL} . \mathrm{L}^{-1}\right)$ and 6 levels of the factor period of storage $(0,7,14,21,28$ and 35 days of cool storage, on the set up 1 , and $0,7+4,14+4,21+4,28+4$ and 35 days of cool storage +4 days of room storage, on the set up 2 ), with 3 replicates. The experimental units were built up with 2 fruits. The use of 1-methylcyclopropene on the fruit kept under refrigeration reduces the weight and ascorbic acid losses, delaying but not avoiding the ripening. The treatment with $150 \mathrm{~nL} . \mathrm{L}^{-1}$ is not more efficient than that with $100 \mathrm{~nL} . \mathrm{L}^{-1}$, in accord to the analysed chemical characteristics. The increased weight loss of fruits stored under environmental conditions promoted expressive shriveling and loss of quality, on the basis of analyses of soluble solids, soluble sugars and titratable acidity.

Index terms: Mangifera indica L., conservation, 1-MCP, shelf-life.
\end{abstract}

\footnotetext{
${ }^{1}$ (Trabalho 127-08). Recebido em: 26-05-2008. Aceito para publicação em: 02-12-2008. Parte de tese de Mestrado do primeiro autor, apresentado ao Departamento de Ciência dos Alimentos - DCA/UFLA.

${ }^{2}$ Eng $^{\circ}$. Agr ${ }^{\circ}$., Doutoranda em Produção Vegetal da FCAV/UNESP -Campus de Jaboticabal. Via de Acesso Prof. Paulo Donato Castellane, s/n, 14884-900, Jaboticabal-SP- e-mail: ellendollhojo@yahoo.com.br; ronaldo.hojo@yahoo.com.br

${ }^{3} \mathrm{Eng}^{\circ}$. Agr ${ }^{\circ}$., Professor Adjunto do Departamento de Química/Universidade Federal de Lavras -cx. P. 37, 37200-00, LavrasMG. e-mail: celeste@ufla.br

${ }^{4}$ Eng $^{\circ}$. Agr ${ }^{\circ}$. Doutoranda em Fitotecnia da Universidade Federal de Lavras. cx. P. 37, 37200-00, Lavras-MG. e-mail: siasmar@yahoo.com.br

${ }^{5}$ Eng $^{\circ}$. Agr ${ }^{\circ}$., Professor Adjunto do Departamento de Ciência dos Alimentos/Universidade Federal de Lavras -cx. P. 3037, 37200-00, Lavras-MG. e-mail: evbvboas@ufla.br
} 


\section{INTRODUÇÃO}

A manga é o segundo fruto tropical mais importante cultivado no mundo (Agrianual, 2005). Entretanto, é altamente perecível, tornando a distribuição para centros distantes limitada pela curta vida pós-colheita.

Pelo fato de tratar-se de uma fruta sazonal e produzida em vários países, é de extrema importância viabilizar técnicas para o melhor aproveitamento e a conservação, tanto em termos econômicos quanto nutricionais. Para isso, tornam-se valiosos os estudos com o objetivo de conhecer melhor as características e as transformações físicas, químicas, bioquímicas e sensoriais da manga durante os estádios de maturação, armazenamento e processamento, para a obtenção de melhor qualidade e aperfeiçoamento da industrialização.

O potencial brasileiro para a exportação de manga pode ser mais bem explorado, principalmente porque a produção nacional não coincide com a de alguns dos principais concorrentes e também pela grande demanda européia por frutas tropicais. Entretanto, para que o Brasil participe mais efetivamente do mercado internacional, é necessário o desenvolvimento de novas tecnologias, além do aprimoramento das existentes, principalmente nas áreas de pós-colheita e processamento. Entre as modernas técnicas aplicadas na pós-colheita de frutos está a aplicação de inibidores de etileno, que promovem retardo no amadurecimento, permitindo estender a vida útil de prateleira e, assim, o prazo de comercialização.

O 1-metilciclopropeno (1-MCP), inibidor da ação do etileno, vem sendo utilizado em vários frutos, apresentado resultados efetivos, e proporcionando controle do amadurecimento e da senescência. O 1MCP é um gás que bloqueia a ação do etileno por ligar-se ao receptor na membrana celular (Sisler et al., 1996), reduzindo severamente as mudanças associadas ao amadurecimento (Faubion, 2000) e prolongando a vida pós-colheita dos frutos. Esse produto vem sendo considerado uma das mais importantes ferramentas da pós-colheita no armazenamento e no transporte de frutas sensíveis ao etileno, por manter a qualidade como se fossem recém-colhidas (Chitarra \& Chitarra, 2005).

A concentração de 1-MCP, necessária para promover a inibição da ação do etileno, varia conforme a espécie, a cultivar, o estádio de maturação, a temperatura de exposição, o tempo de exposição e a produção de novos receptores de etileno nas membranas celulares (Blankenship \& Dole, 2003).
Visando a estabelecer condições que ampliem o período de comercialização de mangas, com manutenção da qualidade no amadurecimento subsequente à colheita, o objetivo deste trabalho foi verificar a qualidade de mangas da cv. Palmer tratadas com 1-metilciclopropeno mantidas sob armazenamento refrigerado e sob armazenamento refrigerado associado à exposição à temperatura ambiente por quatro dias.

\section{MATERIAL E MÉTODOS}

Foram conduzidos dois experimentos na mesma época, em armazenamento refrigerado e em condição ambiente, utilizando-se de frutos de mangueira (Mangifera indica L.), cv. Palmer, provenientes de um mesmo pomar com 4 anos de idade, localizado no município de Livramento de Nossa Senhora, Bahia $\left(13^{\circ} 17^{\prime}\right.$ a $15^{\circ} 20^{\prime}$ de latitude sul e $41^{\circ} 05^{\prime}$ a $43^{\circ} 36^{\prime}$ de longitude oeste).

Os frutos foram colhidos manualmente, pela manhã, quando atingiram a maturidade fisiológica, definida a partir da coloração da polpa (cor creme), escala de coloração indicada pela GTZ (1992). Após a colheita, os frutos foram acondicionados em contentores e transportados até o Laboratório de Pós-Colheita de Frutas e Hortaliças do Departamento de Ciência dos Alimentos da Universidade Federal de Lavras, em Minas Gerais.

Os frutos analisados no experimento sob refrigeração apresentaram os seguintes valores médios: 545 a 560 g, 127,6 a 128,6 mm de comprimento, 85,2 a $86,1 \mathrm{~mm}$ de largura e 90,0 a $90,4 \mathrm{~mm}$ de espessura. Já os frutos analisados no estudo sob condição ambiente apresentaram valores médios variando entre 530 e $540 \mathrm{~g}, 125,2$ e $128,6 \mathrm{~mm}$ de comprimento, 83,9 e 85,2 mm de largura e 88,8 e 90,2 mm de espessura.

As mangas foram selecionadas em função do tamanho, da cor e da ausência de danos, lavadas e sanificadas com hipoclorito de sódio a $300 \mathrm{mg} . \mathrm{L}^{-1}$, por 15 minutos. A aplicação foi realizada em caixas de isopor com volume de 100 litros, hermeticamente fechadas, utilizando 1-metilciclopropeno (1-MCP), na formulação pó, com $0,14 \%$ de ingrediente ativo do produto Smartfresh $\AA$, por um período de 12 horas, à temperatura de $22^{\circ} \mathrm{C}$, para o $2^{\circ}$ e o $3^{\circ}$ grupos. Os frutos-testemunha foram colocados em câmara hermética, por 12 horas, porém sem a aplicação de 1MCP.

Depois de 12 horas da aplicação dos tratamentos, os frutos foram armazenados em câmara fria a $10^{\circ} \mathrm{C} \pm 1$ e 80 a $90 \%$ de UR, por um período de 35 dias. A cada 7 dias, foram retirados os 6 frutos de 
cada tratamento para as análises. Os dois experimentos foram conduzidos nas mesmas condições; entretanto, no experimento 1, as mangas foram analisadas após a remoção da câmara de refrigeração, aos $7 ; 14 ; 21 ; 28$ e 35 dias e, no experimento 2, as mangas foram submetidas às análises após a permanência em temperatura ambiente, por 4 dias, visando a simular o período de comercialização. As condições ambientais apresentaram temperatura de $21,35^{\circ} \mathrm{C}$ a $24,90^{\circ} \mathrm{Ce} \mathrm{UR}$ de $66,4 \%$, registradas por termohigrógrafo.

Os parâmetros considerados foram: massa do fruto (g) - determinada com auxílio de balança semianalítica; dimensões (mm) - com o uso de paquímetro foram medidos o comprimento (da base do pedúnculo à outra extremidade), a largura (diâmetro transversal maior) e a espessura (diâmetro transversal menor); perda de massa (\%) - foi considerada a diferença entre a massa inicial do fruto e aquela obtida a cada intervalo de tempo da amostragem, utilizando-se de balança semianalítica; sólidos solúveis (\%) - determinados em refratômetro digital, segundo a AOAC (1992); acidez titulável (g de ácido cítrico. $100 \mathrm{~g}^{-1}$ de polpa) - determinação por titulação com solução de $\mathrm{NaOH} 0,1 \mathrm{~N}$ e o indicador fenolftaleína, de acordo com o Instituto Adolfo Lutz (1985); pH - determinado, utilizando-se de potenciômetro, segundo técnica da AOAC (1992); amido (\%) - determinado após lavagem dos açúcares solúveis com etanol $80 \%$, pela hidrólise ácida do resíduo e pela autoclavagem, sendo os açúcares provenientes da hidrólise quantificados espectrofotometricamente a 510nm, de acordo com a técnica de Somogyi \& Nelson (1944); relação sólidos solúveis/acidez titulável - obtida pela divisão do teor de sólidos solúveis pela acidez titulável; açúcares solúveis totais, açúcares redutores e açúcares não-redutores ( $\mathrm{g}$ de glicose $100 \mathrm{~g}^{-1}$ de polpa) - extração pelo método de Lane-Enyon (AOAC, 1992) e quantificação pelo método descrito por Noelting \& Bernfeld (1948); ácido ascórbico (mg de ácido ascórbico. $100 \mathrm{~g}^{-1} \mathrm{de}$ polpa) - após a oxidação a ácido deidroascórbico, foi determinado pelo método colorimétrico com 2,4 dinitrofenilhidrazina, segundo Strohecker \& Henning (1967).

$\mathrm{O}$ delineamento estatístico utilizado foi o inteiramente casualizado, disposto em esquema fatorial $3 \times 6$, com 3 repetições, no qual o primeiro fator correspondeu às doses de 1-MCP $\left(0 ; 100\right.$ nL.L $L^{-1} \mathrm{e}$ 150 nL.L ${ }^{-1}$ ) e o segundo, ao tempo de armazenamento, sendo que, para o experimento sob refrigeração, os níveis foram $0 ; 7 ; 14 ; 21 ; 28$ e 35 dias, e para o experimento sob condição ambiente, os níveis foram $0 ; 7+4 ; 14+4 ; 21+4 ; 28+4$ e 35 dias sob refrigeração +4 dias em condição ambiente. Cada parcela foi composta por 2 frutos.

A massa e as dimensões dos frutos foram determinadas apenas para a caracterização, enquanto os dados das demais variáveis foram submetidos à análise de variância por meio do programa SISVAR. Para a descrição das variáveis em função dos períodos de armazenamento, foram feitas análises de regressão, e os modelos polinomiais foram selecionados, observando-se a significância do teste $\mathrm{F}$ para cada modelo e os respectivos coeficientes de determinação.

\section{RESULTADOS E DISCUSSÃO}

Observou-se um aumento significativo da perda de massa dos frutos ao longo do armazenamento refrigerado, observando-se os maiores valores no tratamento-testemunha, $10 \%$, seguido pelos 150 nL.L ${ }^{-1}, 8,6 \%$, e pelos 100 nL.L ${ }^{-1}$, $8,4 \%$ de perda no final do armazenamento (Figura 1A). No entanto, a perda de massa verificada não foi suficiente para causar murchamento ou comprometer a aparência externa dos frutos. Cocozza et al. (2004) avaliando mangas 'Tommy Atkins' tratadas com 1MCP nas doses 30; 120 e 240 nL.L ${ }^{-1}$ e armazenadas a $12^{\circ} \mathrm{C}$, por 21 dias, observaram redução da perda de massa $(4,07 \%)$ nos frutos tratados com 1-MCP, em todas as doses, constatando menor perda de massa em relação ao controle $(4,50 \%)$.

Por outro lado, observou-se aumento ainda mais expressivo da perda de massa dos frutos durante o armazenamento refrigerado, sucedido pela exposição à condição ambiente, atingindo 16,55\%, independentemente da aplicação de 1-MCP (Figura 1B). Portanto, a temperatura e a umidade relativa de armazenamento evidenciaram a suscetibilidade do fruto à perda de massa. Comparativamente, os frutos expostos à condição ambiente perderam mais massa do que os frutos armazenados sob refrigeração, devido à temperatura mais alta e à menor umidade relativa durante a exposição à condição ambiente.

Avaliando mangas 'Tommy Atkins' após aplicação pós-colheita de 1-MCP sob temperatura ambiente $\left(27,5 \pm 1,2^{\circ} \mathrm{C}\right)$, nas doses $30 ; 120$ e 240 nL.L ${ }^{-1}$, Cocozza et al. (2004), observaram que o 1-MCP reduziu a perda média de massa $(5,61 \%, 5,72 \%$ e $5,95 \%$, respectivamente), inferior àquela observada no controle $(6,63 \%)$. Após 14 dias, as mangas apresentavam $11,89 \%$ de perda de massa.

Após o armazenamento refrigerado por 14 dias e a permanência à temperatura ambiente por 4 dias, 0 efeito da perda de massa comprometeu a aparência 
(murchamento) dos frutos-testemunha, ao passo que, nos frutos tratados com 1-MCP, o comprometimento foi verificado aos 21 dias sob refrigeração, acompanhados pelos 4 dias à temperatura ambiente. Dessa forma, conclui-se que o 1-MCP foi capaz de aumentar a vida útil pós-colheita das mangas por mais 7 dias.

Os frutos dos três tratamentos apresentaram o mesmo comportamento relacionado aos sólidos solúveis durante o armazenamento refrigerado e a exposição à condição ambiente, a variável aumentou linearmente até o final, nos frutos armazenados sob refrigeração, e apresentou tendência de elevação até o 32 ㅇa, sucedida por um leve decréscimo, nos frutos expostos à temperatura ambiente por quatro dias (Figuras 1C e D). É possível que o decréscimo verificado esteja associado ao consumo dos próprios sólidos solúveis nos processos respiratórios. Os frutos tratados com 1-MCP apresentaram menores aumentos de sólidos solúveis em relação à testemunha durante o armazenamento refrigerado e a exposição à condição ambiente, o que sugere diminuição no metabolismo dos referidos frutos tratados com 1-MCP. Contudo, em mangas 'Kensington Pride', 'Kent" e 'Tommy Atkins ', alguns estudos relataram que o 1-MCP não apresentou efeito significativo em retardar o acúmulo da considerada variável, o que sugere que, nessas cultivares, o teor de sólidos solúveis pode não ser influenciado pelo etileno (Hofman et al., 2001; Garcia Estrada et al., 2001; Cocozza et al., 2004). O mesmo fenômeno foi verificado em maçã (Rupasinghe et al., 2000), tomate (Moretti et al., 2001), mamão (Jacomino et al., 2002) e banana (Golding et al., 1998), porém, em abacaxi e graviola, foram observados efeitos transitórios do 1MCP em inibir o acúmulo dos sólidos solúveis (Selvarajah et al., 2001; Lima et al., 2001).

Os frutos não apresentaram uma regularidade nas reações da acidez titulável durante o período de armazenamento refrigerado, mas, ao final, os frutos que receberam a dose de 100 nL.L L $^{-1}$ apresentaram maior acidez em relação aos outros dois tratamentos (Figura 1E). Considerando-se o armazenamento refrigerado sucedido pela exposição à temperatura ambiente, observa-se que os frutos submetidos aos três tratamentos sofreram redução expressiva da acidez titulável (Figura 1F). Porém, no final do referido armazenamento, observou-se súbito aumento para os frutos tratados com 100 nL.L ${ }^{-1}$ de 1 -MCP, provavelmente em virtude da ocorrência de fermentação, com o início da senescência. A redução da acidez é uma decorrência natural da evolução da maturação, na qual os ácidos orgânicos são metabolizados na via respiratória e convertidos em moléculas não-ácidas (Pech, 2002). Os frutos que não receberam 1-MCP apresentaram menor percentagem de ácido cítrico. Teores mais altos de acidez pelo uso do 1-MCP têm sido descritos para frutos climatéricos (Wills \& Ku, 2002), mangas (Garcia Estrada et al., 2001; Cocozza et al. 2004), maçãs (Argenta et al., 2000; Krammes et al., 2001) e graviolas (Lima et al., 2001).

Quanto ao pH, observou-se aumento durante o armazenamento refrigerado e a exposição à condição ambiente em todos os tratamentos (Figuras 2A e 2B). As diferenças de $\mathrm{pH}$, apesar de estaticamente significativas, foram muito pequenas. Já os frutos submetidos ao 1-MCP e armazenados sob refrigeração e expostos à condição ambiente foram os que apresentaram o menor $\mathrm{pH}$ durante $\mathrm{o}$ referido armazenamento.

Durante o amadurecimento de frutos, notamse um aumento no $\mathrm{pH}$ e um decréscimo na acidez (Medlicott et al., 1986). Em mangas, alguns estudos reiteram os processos descritos (Evangelista et al., 1996; Rocha et al., 2001; Gowda \& Huddar, 2001; Morais et al., 2002), inclusive para a manga Palmer (Megale, 2002). No presente trabalho, os mesmos fenômenos foram observados nos frutos expostos à condição ambiente durante o armazenamento. No entanto, nos frutos armazenados sob refrigeração, houve pequeno aumento no $\mathrm{pH}$, com a acidez elevada e apresentando pequenas oscilações.

Observou-se aumento da relação entre sólidos solúveis e acidez titulável durante todo o período de armazenamento refrigerado (Figura 2C). Nos frutos da testemunha, a relação foi menor do que nos tratados com 1-MCP, provavelmente pelo fato de o metabolismo naqueles frutos estar mais acelerado, ou seja, eles podem estar utilizando os açúcares na respiração em maior proporção que os frutos tratados com 1-MCP. No armazenamento refrigerado, sucedido pela exposição à condição ambiente, houve aumento da relação entre sólidos solúveis e acidez titulável até o $32^{\circ}$ dia, seguido por um decréscimo decorrente da elevação da acidez titulável e da diminuição dos sólidos solúveis no final do processo (Figura 2D).

Cocozza et al. (2004) observaram que não houve influência dos tratamentos de 1-MCP em mangas 'Tommy Atkins' na relação considerada. Entretanto, com banana, Sales (2002) relatou comportamento contrário, observou valores menores da relação nos frutos tratados com 1-MCP.

Os maiores teores de amido foram observados nos frutos-testemunha, tanto sob armazenamento refrigerado quanto sob armazenamento refrigerado sucedido pela exposição 
à condição ambiente (Figuras $2 \mathrm{E}$ e $2 \mathrm{~F}$ ). Com o decorrer do tempo, em ambos os modos de armazenamento descritos, verificou-se contínua diminuição dos referidos teores de amido, ratificando o estudo implementado por Rocha et al. (2001), que observaram o mesmo decréscimo durante o amadurecimento em mangas 'Tommy Atkins'. Simultaneamente à redução nos teores de amido, notou-se aumento quase contínuo nos teores de açúcares solúveis totais até o final do armazenamento refrigerado e do armazenamento refrigerado sucedido pela exposição à condição ambiente, nos três tratamentos (Figuras 3A e 3B), provavelmente decorrente da hidrólise do amido em açúcares, como glicose, durante o processo de amadurecimento (Cardello \& Cardello, 1998). Os frutos da testemunha e os frutos tratados com 100 nL.L ${ }^{-1}$ de $1-\mathrm{MCP}$ apresentaram as menores percentagens de açúcares solúveis totais no final do armazenamento refrigerado (respectivamente, 9,91\% e 9,78\%), enquanto os frutos tratados com 150 nL.L ${ }^{-1}$ de 1 -MCP apresentaram a maior percentagem $(10,20 \%)$. Considerando os frutos expostos à condição ambiente, o aumento do teor de açúcares solúveis totais foi mais acentuado nos frutos-testemunha, indicando um metabolismo mais acelerado do amido em relação aos frutos tratados com 1-MCP. Entretanto, verificou-se uma redução do caráter nos referidos frutos após o 25ํํㄹia, provavelmente devido à utilização dos compostos como substratos na respiração. O acúmulo de açúcares solúveis totais durante o processo de amadurecimento foi verificado em mangas 'Amrapali' (Singh et al., 1998) e mangas 'Tommy Atkins' (Evangelista, 1999; Morais et al., 2002; De Sousa et al., 2002; Cocozza et al., 2004), independentemente dos tratamentos.

Bernades Silva et al. (2003) avaliaram a evolução dos açúcares solúveis durante o desenvolvimento e o amadurecimento de mangas e notaram que as cultivares Tommy Atkins e Haden apresentaram o maior acúmulo, cerca de $12 \%$. As cultivares Van Dyke e Palmer foram as que menos acumularam, cerca de $7,30 \%$ e $9,79 \%$, respectivamente.

O conteúdo dos açúcares redutores aumentou quase continuamente ao longo do processo de amadurecimento, independentemente dos tratamentos (Figuras 3C e 3D). Sob armazenamento refrigerado sucedido pela exposição à condição ambiente, observou-se menor elevação dos açúcares redutores, ao final do processo, nos frutos tratados com 1-MCP, indicando menor hidrólise de amido.

Analogamente, observou-se também aumento nos teores dos açúcares não-redutores com o avanço da maturação, nos três tratamentos (Figuras 3E e 3F), fenômeno condizente ao verificado por Melo Neto et al. (1999). Considerando-se o armazenamento refrigerado sucedido pela exposição à condição ambiente, os respectivos aumentos nos teores dos açúcares não-redutores verificados nos frutos tratados com 1-MCP, até o 32을 dia, foram menos acentuados do que o observado nos frutostestemunha, indicando, mais uma vez, que o 1-MCP reduziu o metabolismo. Um aumento nos teores de sacarose durante o processo de amadurecimento também foi observado por Evangelista (1999), em mangas 'Tommy Atkins', por Castrillo et al. (1992), em mangas 'Haden', e por Bernades Silva et al. (2003), em mangas 'Van Dyke', 'Palmer', 'Haden' e 'Tommy Atkins'.

Rocha et al. (2001) observaram, em mangas 'Tommy Atkins', que o aumento nos teores de açúcares (solúveis totais, redutores e não-redutores) e de sólidos solúveis durante a maturação correspondente à redução concomitante do conteúdo de amido, demonstrando uma crescente conversão da referida molécula, em açúcares simples. O mesmo comportamento foi observado para as cultivares Rosa, Coité, Jasmim, Espada e Itamaracá, por Maia et al. (1986).

Sob efeito de $100 \mathrm{~nL} . \mathrm{L}^{-1}$ de $1-\mathrm{MCP}$, os teores de ácido ascórbico apresentaram-se maiores em relação ao tratamento-testemunha, após o $25^{\circ}$ dia, e em relação à dose de 150 nL.L ${ }^{-1}$, até os 35 dias de armazenamento refrigerado (Figura 4A). As concentrações altas estão relacionadas à maior síntese de intermediários metabólicos precursores do ácido ascórbico, enquanto as baixas concentrações estão associadas à oxidação dos ácidos orgânicos durante o amadurecimento.

Cocozza et al. (2004), avaliando mangas 'Tommy Atkins', verificaram que os teores de ácido ascórbico foram maiores nos frutos tratadas com 1$\mathrm{MCP}$, até os 20 dias de armazenamento refrigerado (38,32mg.100 $\mathrm{g}^{-1}$ de polpa), com destaque para a dose de 100 nL.L ${ }^{-1}$. Os mesmos autores supõem que a atividade respiratória nos frutos tratados com 1-MCP pode sinalizar maior acúmulo de glicose utilizada na respiração do fruto, favorecendo a síntese do ácido ascórbico, conforme sugeriu Evangelista (1999), quando tratou mangas da mesma cultivar com cloreto de cálcio na pré-colheita. Entretanto, no armazenamento refrigerado sucedido pela exposição à condição ambiente, os teores de ácido ascórbico dos frutos sob efeito de 1-MCP, nas duas doses aplicadas, apresentaram-se inferiores em relação ao tratamento-testemunha, provavelmente em virtude do menor metabolismo de açúcares (Figura 4B). 

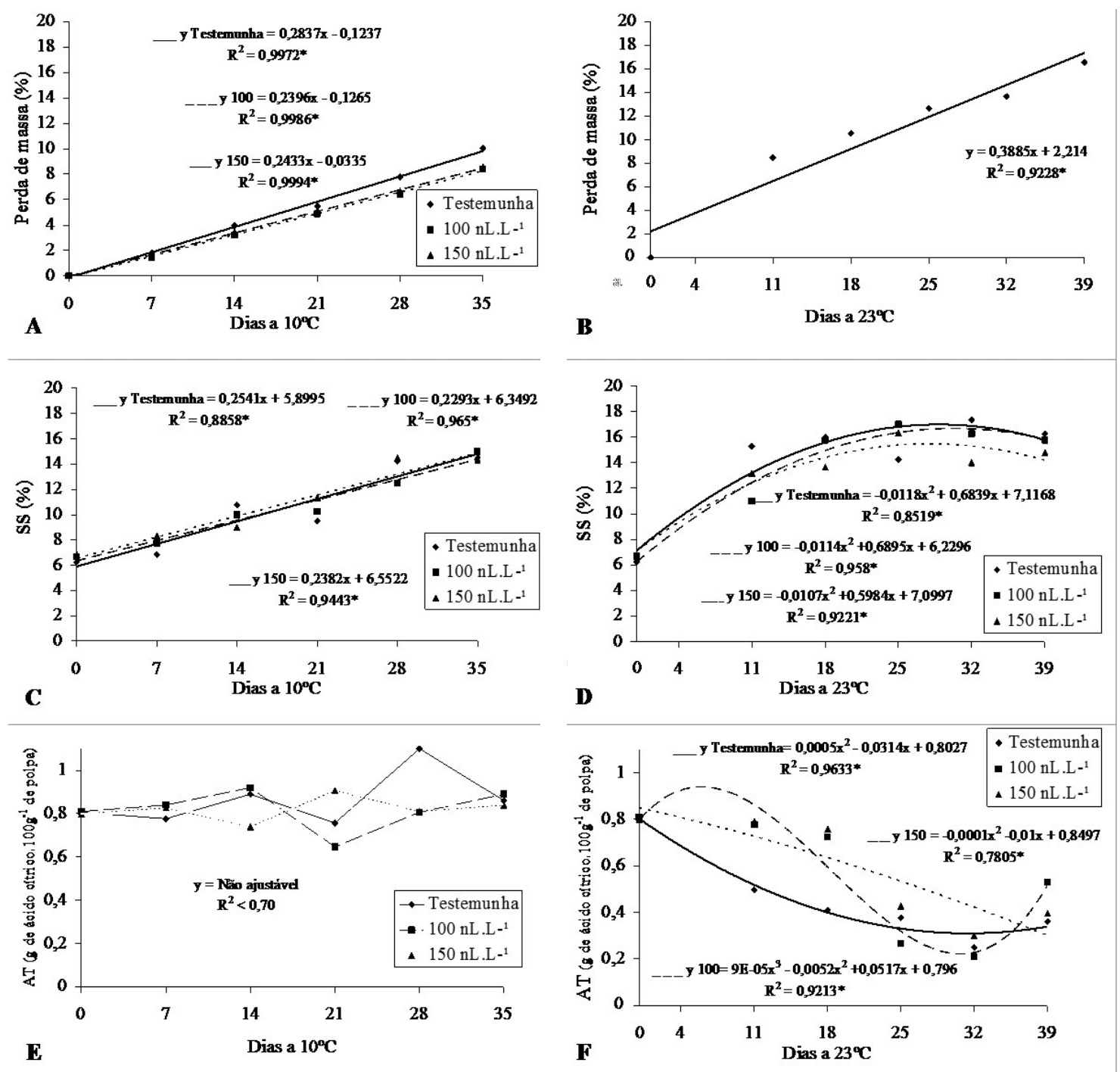

FIGURA 1 - Perda de massa (A e B), sólidos solúveis (C e D) e acidez titulável (E e F) em mangas 'Palmer“ submetidas ao 1-MCP e armazenadas sob temperatura refrigerada $\left(10 \pm 1^{\circ} \mathrm{C}\right)$ e expostas à temperatura ambiente por 4 dias. 

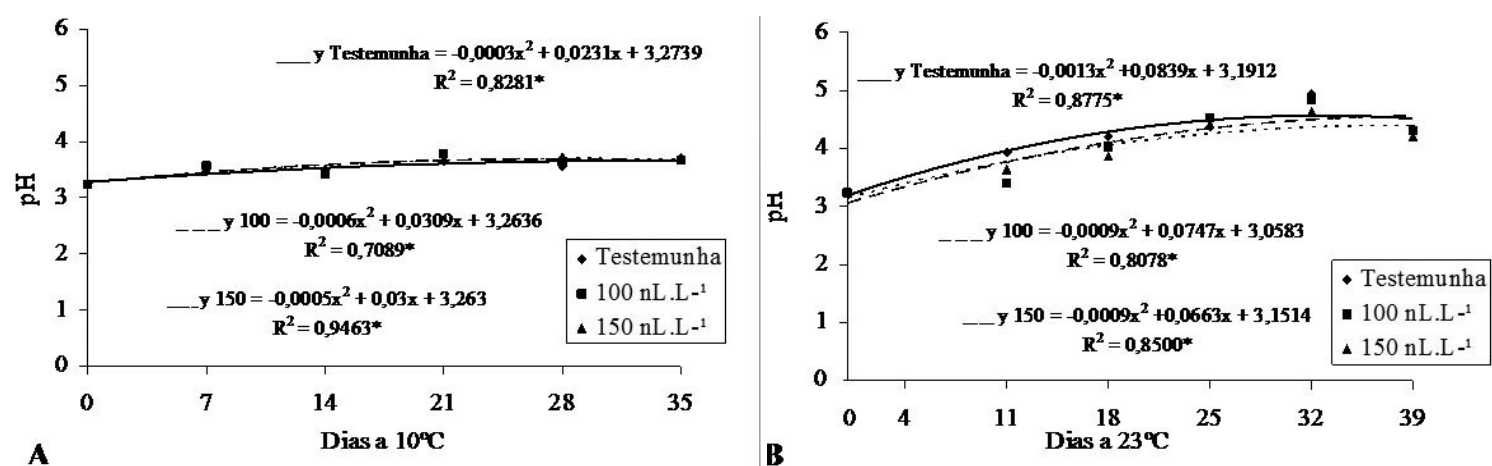

B
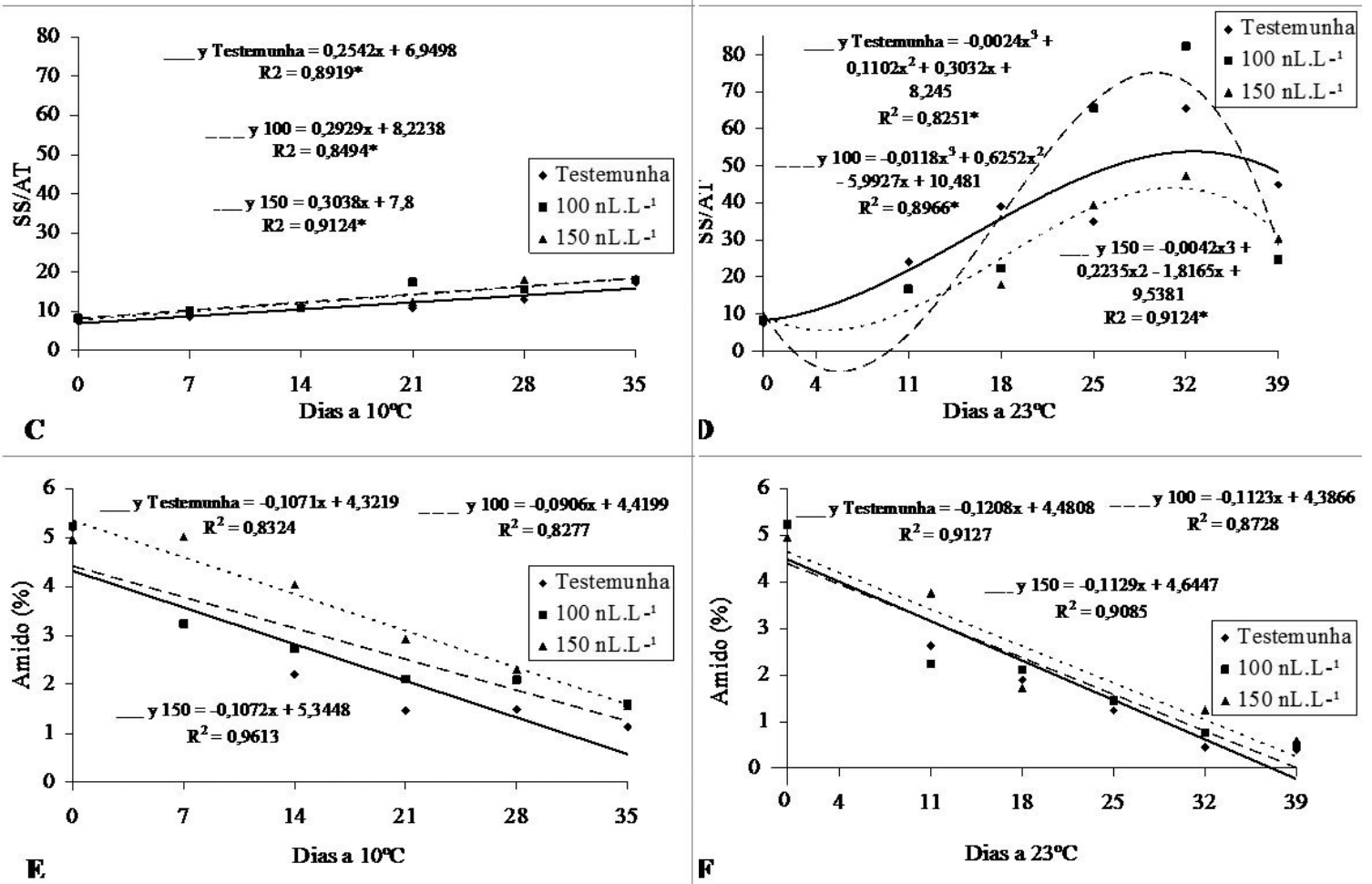

FIGURA 2 - pH (A e B), relação entre sólidos solúveis e acidez titulável (C e D) e amido (E e F) em mangas 'Palmer' submetidas ao 1-MCP e armazenadas sob temperatura refrigerada $\left(10 \pm 1^{\circ} \mathrm{C}\right)$ e expostas à temperatura ambiente por 4 dias. 

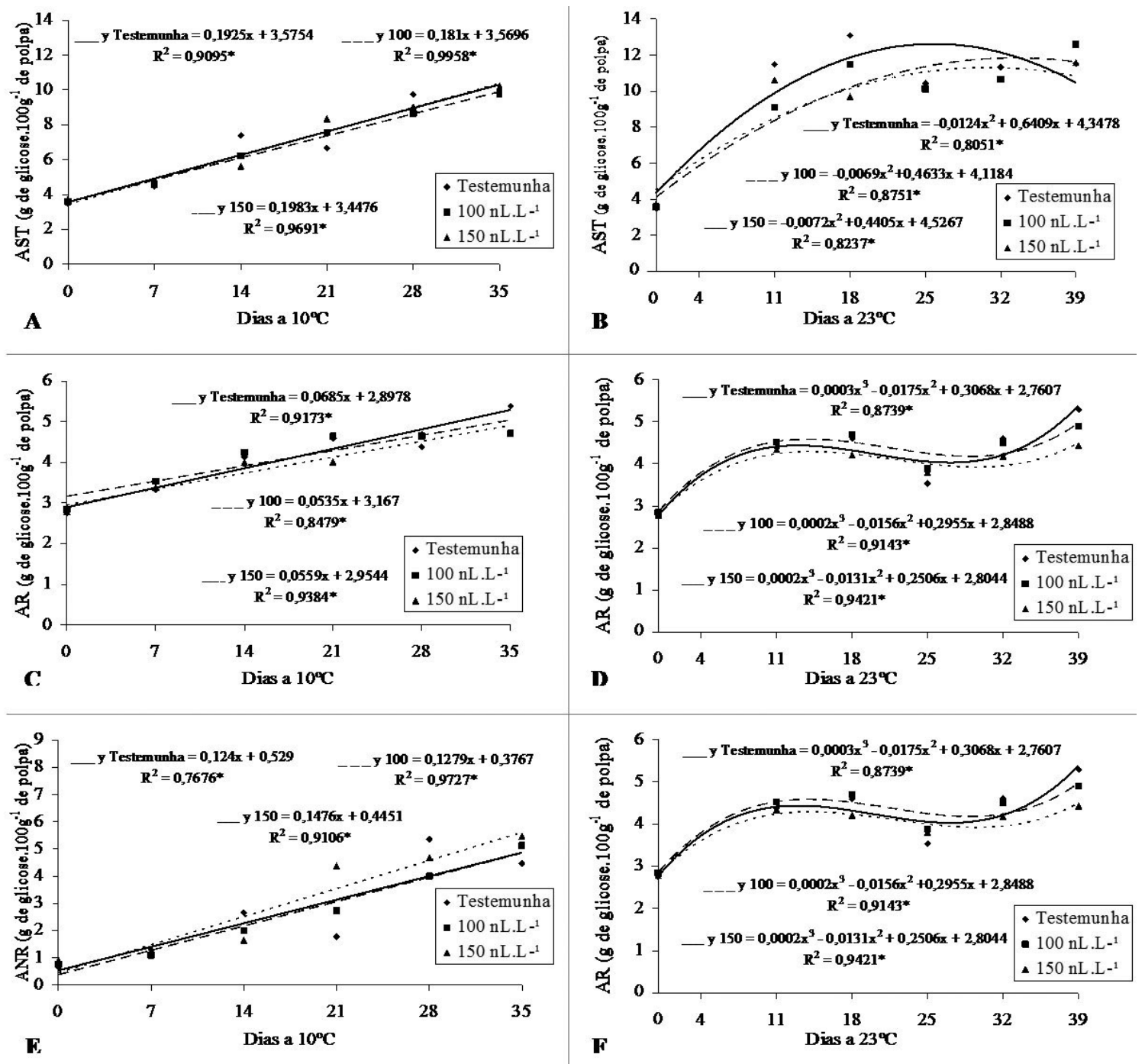

FIGURA 3 - Açúcares solúveis totais (A e B), açúcares redutores (C e D) e açúcares não-redutores (E e F) em mangas 'Palmer' submetidas ao 1-MCP e armazenadas sob temperatura refrigerada (10 \pm $1^{\circ} \mathrm{C}$ ) e expostas à temperatura ambiente por 4 dias.
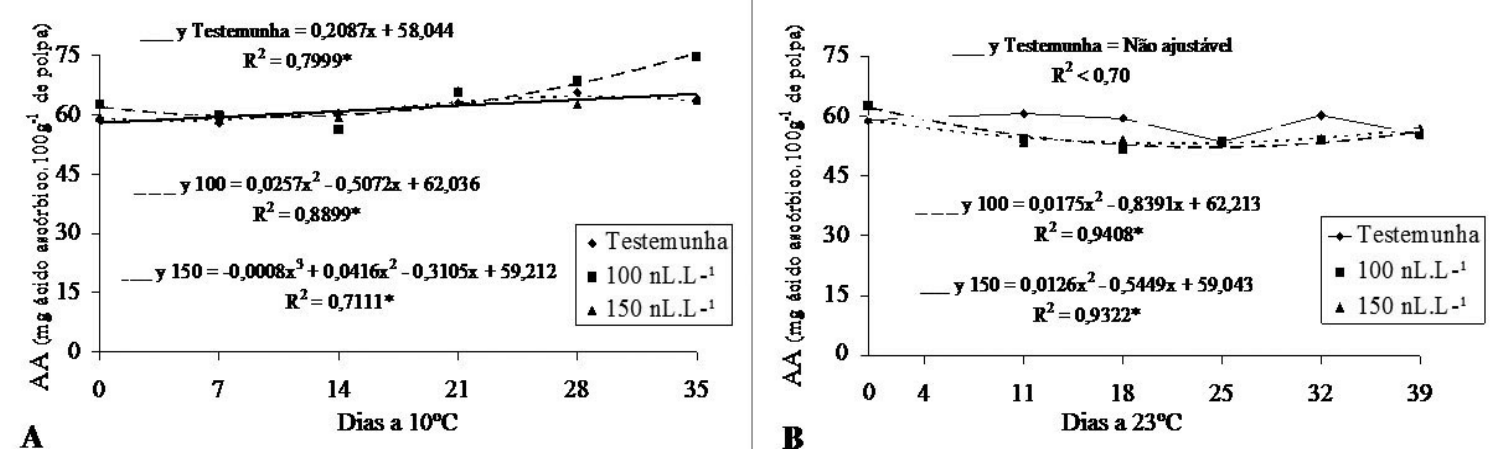

FIGURA 4 - Teor de ácido ascórbico em mangas 'Palmer' submetidas ao 1-MCP e armazenadas sob temperatura refrigerada $\left(10 \pm 1^{\circ} \mathrm{C}\right)(\mathrm{A})$ e expostas à temperatura ambiente por 4 dias (B). 


\section{CONCLUSÕES}

1- O uso de 1-MCP em mangas 'Palmer', mantidas sob refrigeração, reduz as perdas de massa e ácido ascórbico, retardando, mas não impedindo o amadurecimento.

2- O tratamento com 150 nL.L ${ }^{-1}$ não é mais eficiente que o com $100 \mathrm{~nL} . \mathrm{L}^{-1}$, pelas características químicas analisadas.

3- As mangas 'Palmer' expostas à condição ambiente, por quatro dias, apresentam perda de qualidade, com base nas análises de sólidos solúveis, açúcares solúveis e acidez titulável.

\section{AGRADECIMENTOS}

À CAPES, pela concessão de bolsa de mestrado, e à empresa ROHM HAAS, pelo fornecimento do 1-Metilciclopropeno.

\section{REFERÊNCIAS}

AGRIANUAL 2005: anuário da agricultura brasileira. São Paulo: FNP Consultoria e comércio, 2003. p 392398.

AOAC - ASSOCIATION OF OFFICIAL ANALYTICAL CHEMISTRY. Official methods of analysis of the Association of Official Analytical Chemistry. $12^{\text {th }}$ ed. Washington, 1992.1015 p.

ARGENTA, L. C.; MATTHEIS, J. P.; FAN, X. Controle do amadurecimento de frutas - manipulação da ação do etileno com 1-metilciclopropeno para preservação pós-colheita de maçãs e peras. In: CONGRESSO BRASILEIRO DE FRUTICULTURA, 16., 2000, Fortaleza. Palestras... Fortaleza: EMBRAPA Agroindústria Tropical/SBF, 2000a. p. 236-243. CDROM.

BERNADES SILVA, A. P. F.; LAJOLO, F. M.; CORDENUNSI, B. R. Evolução dos teores de amido e açúcares solúveis durante o desenvolvimento e amadurecimento de diferentes cultivares de manga, Ciência e tecnologia de Alimentos, Campinas, v. 23, n. 3, p. 116-120, dez. 2003.

BLANKENSHIP, S.; DOLE, J. M. 1Methylcyclopropene: a review. Postharvest biology and technology, Amsterdam, v. 28, p. 1-25, 2003.
CARDELLO, H. M. A. B.; CARDELLO, L. Teor de vitamina $\mathrm{C}$, atividade de ascorbato oxidase e perfil sensorial de manga (Mangifera indica L.) var. Haden, durante o amadurecimento. Ciência e Tecnologia de Alimentos, Campinas, v. 18, n. 2, p. 211-217, maio/jul. 1998.

CASTRILLO, M.; KRUGER, N. J.; WHATLEY, F. R. Sucrose metabolism in mango fruit during ripening. Plant Science, Clare, v. 84, n. 1, p. 45-51, 1992.

CHITARRA, M. I. F.; CHITARRA, A. B. Pós-colheita de frutos e hortaliças: fisiologia e manuseio. 2.ed. Lavras: UFLA, 2005. 783 p.

COCOZZA, F. M.; PEREIRA, M. E. C.; ALVES, R. E.; FILGUEIRAS, H. A. C.; JORGE, J. T. Respiration rate and chemical characteristics of cold stored. Acta Horticulturae, Amsterdam, v. 645, p. 645-650, 2004.

DE SOUZA, J. P.; PRAÇA, E. F.; ALVES, R. E.; BEZERRA NETO, F.; DANTAS, F. F. Influência do armazenamento refrigerado em associação com atmosfera modificada por filmes plásticos na qualidade da mangas 'Tommy Atkins' Revista Brasileira de Fruticultura, Jaboticabal, v. 24, n. 3, p. 665-668, dez. 2002.

EVANGELISTA, R. M. Qualidade de Mangas 'Tommy Atkins' armazenadas sob refrigeração e tratadas com cloreto de cálcio pré-colheita. 1999. 129 f. Tese (Doutorado em Ciência dos Alimentos) Universidade Federal de Lavras, Lavras, 1999.

EVANGELISTA, R. M.; CHITARRA,A. B.; GOLDON, I. S. Efeito da aplicação de ceras comerciais na póscolheita de manga (Mangifera indica L.) cv. Tommy Atkins. Revista Brasileira de Fruticultura, Jaboticabal, v. 18, n. 1, p. 105-113, 1996.

FAUBION, D. Could new ethylene inhibitor work on fruit. Good Fruit Grower, Pensilvania, v. 50 n. 95, p. 18, 2000.

GARCIA-ESTRADA, R. Effecto de 1metilciclopropeno en la presencia de Colletotrichum gloeosporoides PENZ durante el mercadeo de frutos de mango. Fitopatologia Brasileira, Brasília, v.26, p.462, 2001. Suplemento.

GOLDING, J. B.; SHEARER, D.; WYLLIE, S. G.; MCGLASSON, W. B. Application of 1-MCP and propylene to identify ethylene-dependent ripening processes in mature banana fruit. Postharvest 
Biology and Technology, Amsterdam, v. 14, n. 1, p. 87-98, Sept. 1998.

GOWDA, I. N. D.; HUDDAR, A. G. Studies on ripening changes in mango (Mangifera indica L.) fruits. Journal of Food Science and Technology, Londres, v. 38, n. 2, p. 135-137, Feb. 2001.

GTZ - DEUTSCHE GESELLSCHAFT FÜR TECHNISCHE ZUSAMMENARBEIT. Manual de exportación: frutas tropicales y hortalizas. Eschborn: GTZ, 1992.34 p.

HOFMAN, P. J.; JOBIN-DÉCOR, M.; MEIBURG, G. F.; MACNISH, A. J.; JOYCE, D. C. Ripening and quality responses of avocado, custard apple, mango and papaya fruit to 1-methylcycloprpene. Australian Journal Experimental Agriculture, Melbourne, v.41, p. 567-572, 2001.

INSTITUTO ADOLFO LUTZ. Normas analíticas: métodos químicos e físico-químicos para análise de alimentos. 2. ed. São Paulo, 1985. v. 1, 371 p.

JACOMINO, A. P.; KLUGE, R. A.; BRACKMANN, A.; CAMARGO E CASTRO, P. R. Controle do amadurecimento e senescência de mamão com 1metilciclopropeno. Scientia Agrícola, Piracicaba, v. 59, n. 2, p. 303-308, 2002.

KRAMMES, J. G.; AMARANTE, C. V. ; ARGENTA, L. C. Effects of methylcyclopropene and wax coating on apple fruit ripening during shelf life. In: CONGRESSO BRASILEIRO DE FISIOLOGIA VEGETAL, 8., 2001, Ilhéus. Resumos.... Ilhéus: SBFV, 2001.p. 137.

LIMA, M. A. C.; ALVES, R. E.; FILGUEIRAS, H. A. C.; PEREIRA, M. E. C.; ALMEIDA, A. S.; ENÉAS FILHO, J. Alterações durante a maturação de graviola (Annona muricata L.) submetida a aplicação póscolheita de 1-MCP. Proceedings of the Interamerican Society for Tropical Horticulture, Orlando, v. 45, n. 1, p. 1-5, 2001.

MAIA, G. A.; SILVA, M. DE F. A.; HOLANDA, L. F. F. DE; MONTEIRO, J. C. S.; ORIÁ, H. F.; FIGUEIREDO, R. W. DE. Estudo da maturação de algumas variedades de manga (Mangifera indica L.). Revista Brasileira de Fruticultura, Jaboticabal, v. 8, n. 2, p. 67-74, 1986.

MEDLICOTT, A. P.; BHOGOL, M.; REYNOLDS, S. $\mathrm{B}$. Changes in peel pigmentation during ripening of mango fruit (Mangifera indica var. Tommy Atkins). Annals of Applied Biology, London, v. 109, n. 3, p. 651-656, 1986.

MEGALE, J. Influência do estádio de maturação e da condição de armazenagem em parâmetros sensoriais, químicos e microbiológicos de manga, cultivar Palmer, semi-processada. 2002. $111 \mathrm{f}$. Dissertação (Mestrado em Engenharia Agrícola) Universidade Estadual de Campinas, Campinas, 2002.

MELO NETO, M. L.; CHRISTOFFOLETI, P.J.; SIGRIST, J.M.M.; ALVES, R.M.V. Utilização de embalagens plásticas e refrigeração na conservação da manga (Mangifera indica L.) cv. Palmer. Revista Brasileira de Fruticultura, Jaboticabal, v. 21, n. 2, p. 160-165, 1999.

MORAIS, P. L. D.; FILGUEIRAS, H. A. C.; PINHO, J. L. N.; ALVES, R. E. Ponto de colheita ideal de mangas 'Tommy Atkins'destinadas ao mercado Europeu. Revista Brasileira de Fruticultura, Jaboticabal, v. 24, n. 3, p. 671-675, 2002.

MORETTI, C. L.; MAROUELLI, W. A.; SILVA, W. L. C.; SOUZA, R. M.; ARAÚJO, A. L. Scheduling tomato fruit ripening with 1-methylcyclopropene. Proceedings of the Florida State Horticultural Society, Stuart, v. 114, p. 118-121, 2001.

NOELTING, G.; BERNFELD, P. Sur lês enzymes amylalytiques III. La â-amilase: dosage I' absence I' á-amilase. Helvetica Chimistries Acta, Basel, v. 31, p. 286-290, 1948.

PECH, J. C. Unravelling the mechanisms of fruit ripening and development of sensory quality thought the manipulation of ethylene biosynthesis in melon. In: NATO ADVANCED RESEARCHWORSHOPON BIOLOGYANDBIOTECHNOLOGYOFTHEPLANT HORMONE ETHYLENE, 2002, Murcia. Anais...

ROCHA, R. H. C.; MENEZES, J. B.; MORAIS, E. A.; SILVA, G. G.; AMBROSIO, M. M. de Q.; ALVEZ, M. Z. Uso do índice de degradação de amido na determinação da maturidade da manga 'Tommy Atkins'. Revista Brasileira de Fruticultura, Jaboticabal, v.23, n. 2, p. 302-305, 2001.

RUPASINGHE, H. P. V.; MURR, D. P.; PALIYTH, G.; SKOG, L. Inhibitory effect of 1-MCP on ripening and superficial scald development in 'McIntosh' and 'Delicious' apples. Journal of Horticultural Science and Biotechnology, Ashford, v. 75, n. 3, p. 271-276, 2000. 
SALES, A. N. Aplicação de 1-Metilciclopropeno em banana 'Prata-Anã' armazenada sob baixa temperatura seguida de climatização. 2002. $69 \mathrm{f}$. Dissertação (Mestrado em Ciência dos Alimentos) Universidade Federal de Lavras, Lavras, 2002.

SELVARAJAH, S.; BAUCHOT, A. D.; JOHN, P. Internal browning in cold-storage pineapples is suppressed by a postharvest application of 1methycyclopropene. Postharvest Biology and Technology, Amsterdam, v. 23, n. 2, p. 167-170, 2001.

SINGH, S.; BRAHMACHARI, V. S.; JHA, K. K. Effect of calcium and polyethilene wrapping on storage life of mango. Indian Journal Horticultural, New Delhi, v. 55, n. 3, p. 218-222, 1998.
SISLER, E. C.; BLANKENSHIP, S. M.; GUEST, M. Competition of cyclooctenes for ethylene binding and activity in plants. Plant Growth Regulation, Dortrech, v. 9, n. 2, p. 157-164, 1996.

SOMOGHY, M.; NELSON, N. Notes on sugar determination. Journal of Biological Chemistry, Baltimore, v.153, n.1, p. 153-375, 1944.

STROHECKER, R. L.; HENNING, H. M. Analysis de vitaminas: métodos comprobados. Madrid: Paz Montalvo, 1967. 428 p.

WILLS, R. B. H.; KU, V. V. V. Use of 1-MCP to extend the time to ripen of green tomatoes and postharvest life of ripe tomatoes. Postharvest Biology and Technology, Amsterdam, v. 26, n. 1, p. 85-90, 2002. 